\title{
Robotic hepatectomy for hepatocellular carcinoma: a clinical review
}

\author{
Eric C.H. Lai, Daniel T.M. Chung, Oliver C.Y. Chan, Chung Ngai Tang \\ Department of Surgery, Pamela Youde Nethersole Eastern Hospital, Chai Wan, Hong Kong, China.
}

Correspondence to: Dr. Eric C.H. Lai, Department of Surgery, Pamela Youde Nethersole Eastern Hospital, 3 Lok Man Road, Chai Wan, Hong Kong, China. E-mail: elaichun@gmail.com

How to cite this article: Lai ECH, Chung DTM, Chan OCY, Tang CN. Robotic hepatectomy for hepatocellular carcinoma: a clinical review. Hepatoma Res 2017;3:278-83.

Article history:
Received: 21 Aug 2017
First Decision: 20 Sep 2017
Revised: 4 Oct 2017
Accepted: 26 Oct 2017
Published: 27 Nov 2017
Key words:
Laparoscopy,
hepatectomy,
robotic surgery,
hepatocellular carcinoma

\begin{abstract}
\end{abstract}
\section{INTRODUCTION}

The introduction of minimally invasive surgery (MIS) has revolutionized surgical practice in the past 3 decades. MIS benefits patients in terms of better pain control, shorter hospital stay, earlier recovery, and better cosmesis [Table 1]. Traditionally, liver surgery is considered as one of the most challenging surgeries among the abdominal procedures. Its MIS development is also lag behind other gastrointestinal organs' development. These advanced techniques also require highly experienced laparoscopic skills. Increasing understanding of liver anatomy and advancements in technology have facilitated the development of MIS approach of hepatectomy ${ }^{[1,2]}$. Two international expert consensus conferences on laparoscopic partial hepatectomy were held in Louisville, KY, USA, in 2008 and in Morioka, Japan,

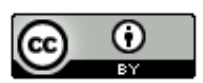

This is an open access article licensed under the terms of Creative Commons Attribution 4.0 International License (https://creativecommons.org/licenses/by/4.0/), which permits unrestricted use, distribution, and reproduction in any medium, as long as the original author is credited and the new creations are licensed under the identical terms.

For reprints contact: service@oaepublish.com

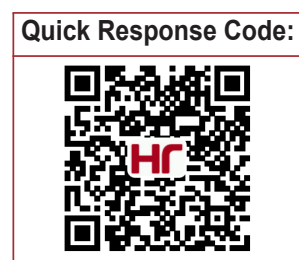


Table 1: Potential advantages of MIS approach of hepatectomy

\begin{tabular}{ll}
\hline Operation & \multicolumn{1}{c}{ Recovery } \\
\hline Improved visualization & Less postoperative pain \\
Reduced blood loss & Earlier mobilization \\
Reduced blood transfusion & Improved perioperative lung function \\
requirement & Fewer wound complications \\
Less intra-abdominal & Reduced perioperative immune \\
adhesion formation & suppression \\
& Improved cosmetic outcome \\
& Shorter recovery time \\
& Shorter hospital stay \\
& Decreased ascites in patients with \\
& portal hypertension \\
\hline
\end{tabular}

MIS: minimally invasive surgery

in 2014, respectively ${ }^{[3,4]}$. The jury in the second consensus meeting concluded that minor laparoscopic hepatectomy should be a standard practice, and major laparoscopic hepatectomy is still in exploration phase. Continued cautious introduction of laparoscopic major hepatectomy was recommended. In a recent review, over 9,000 cases of laparoscopic hepatectomies were performed worldwide, and $65 \%$ of cases were performed for malignant pathologies ${ }^{[5]}$.

The recent introduction of robotic surgical systems has given a new face of MIS. It was developed to overcome the disadvantages of conventional laparoscopic surgery. Well-known advantages of the robotic system such as improved vision via three-dimensional view, magnification, tremor suppression, and the flexibility of the instruments have allowed precise operating techniques in a variety of procedures in general surgery. These features allow the surgeons to perform delicate tissue dissection and precise intra-corporeal suturing. The main drawback of robotic system is the associated cost.

Hepatocellular carcinoma (HCC) is the sixth most common malignancy worldwide and the most common primary liver cancer. Over $80 \%$ of cases HCC grown in a cirrhotic liver ${ }^{[6,7]}$. In view of the benefit of MIS, minimally invasive approach for HCC treatment is increasing continuously adopted ${ }^{[8-11]}$. The postoperative course after MIS approach of partial hepatectomy may also be improved in patients with liver cirrhosis because the abdominal wall is preserved, kinetics of the diaphragm is improved, collateral venous drainage is better and there is less postoperative ascites. Systematic reviews or meta-analyses suggests that laparoscopic partial hepatectomy of HCC is safe and can provide improved patient outcomes when compared to the open approach ${ }^{[12-14]}$. Herein, we review the literature to compare robotic partial hepatectomy to conventional laparoscopic or open partial hepatectomy in terms of perioperative, oncologic, and healthcare costs for $\mathrm{HCC}$.

Studies were identified by searching MEDLINE and PubMed databases for articles from January 2004 to June 2017 using the keywords "laparoscopic hepatectomy", "robotic surgery", "robotic hepatectomy", and "hepatocellular carcinoma". Case reports were not included.

\section{PERIOPERATIVE OUTCOMES}

\section{Robotic vs. open partial hepatectomy}

Three nonrandomized comparative studies compared robotic and open partial hepatectomy ${ }^{[15-17]}$. Patriti et al. ${ }^{[15]}$ from Italy compared outcomes between robotic partial hepatectomy $(n=19)$ and open $(n=69)$ partial hepatectomy at 2 centers for lesions in the right posterior section between January 2007 and June 2012. Matched patients undergoing robotic and open partial hepatectomy showed no significant differences in blood loss (376.3 vs. $457.5 \mathrm{~mL}$ ), intraoperative transfusion rate $(31.6 \%$ vs. $15 \%)$, postoperative transfusion rate $(10.5 \%$ vs. $7 \%)$, mean hospital stay (6.7 vs. 7.9 days), overall complication rate $(15.8 \%$ vs. $13 \%)$ and mortality rate $(0 \%$ vs. $0 \%)$. According to the Clavien-Dindo classification, major (grades 2-4) complications were not significantly different between the 2 groups (5.3\% vs. 1.4\%). Robotic group had significantly longer mean operative time (303 vs. $233 \mathrm{~min}$ ) and inflow occlusion time (75 vs. $29 \mathrm{~min})$ compared with open group. In malignancies, tumorfree margin rates were similar in both groups (R1 resections, $10.5 \%$ vs. $9 \%$ ). Kingham et al. ${ }^{[16]}$ from United States compared outcomes between robotic partial hepatectomy $(n=64)$ during 2010-2014 and open ( $n=64)$ partial hepatectomy during 2004-2012. In the robotic group, $41 \%$ were segmental and $34 \%$ were wedge resections. There was a $6 \%$ open conversion rate. There was a significant shorter median operating time (163 vs. $210 \mathrm{~min}$ ), lower median estimated blood loss (100 vs. $300 \mathrm{~mL}$ ), and shorter median hospital stay (4 vs. 7 days) in robotic group. The complications rates $(10.9 \%$ vs. $14.1 \%)$ and mortality rates $(3 \%$ vs. $1.6 \%)$ were similar in both groups. Eleven of the robotic operations were isolated resections of tumors in segments 2,7 , and 8 . The resection margins of the malignant tumors were similar using both groups. Margins $>10 \mathrm{~mm}$ were found in $16 \%$ of robotic group and $17 \%$ of open group. Daskalaki et al. ${ }^{[17]}$ from United States compared robotic $(n=68)$ and open partial hepatectomies $(n=55)$ during 2009-2013. There was an $8.8 \%$ open conversion rate. Mean estimated blood loss was significantly less in the robotic group (438 vs. $727.8 \mathrm{~mL}$ ). Overall morbidity was significantly lower in the robotic group ( $22 \%$ vs. $40 \%$ ). Clavien-Dindo 
Table 2: Advantages and disadvantages of conventional laparoscopic and robotic approaches

\begin{tabular}{lll}
\hline & Conventional laparoscopic approach & Robotic approach \\
\hline Advantages & Well-developed technology & 3-dimensional magnified view \\
& Less start-up cost & Good dexterity \\
& Less maintenance cost & 7 degrees of freedom in movement \\
& & Elimination of fulcrum effect \\
& Elimination of physiologic tremors \\
Disadvantages & Good in suturing \\
& Tele-surgery \\
& Loss of tactile feedback & More ergonomic in working position \\
& Limited degrees of motion & Total absence of tactile feedback \\
& Fulcrum effect & High start-up cost \\
& Magnification of physiologic tremors & Very expensive in maintenance \\
& New technology with limited evidence \\
\hline
\end{tabular}

grade $3 / 4$ complications were also significantly lower (4.4\% vs. $16.3 \%)$. The length of stay in the intensive care unit (ICU) was significantly shorter for patients who underwent a robotic procedure (2.1 vs. 3.3 days). The mean operating time (293.4 vs. $256 \mathrm{~min}$ ), 30-day mortality (0\% vs. $1.8 \%$ ) and mean hospital stay (6.8 vs. 9.2 days) were similar in both groups. Robotic group had less overall morbidity, ICU, and hospital stay. This translates into decreased average costs for robotic surgery. The mean total cost, including readmissions, was $\$ 37,518$ for robotic approach and $\$ 41,948$ for open approach.

Based on current limited nonrandomized comparative studies, robotic approach has better perioperative outcomes, particularly blood loss and hospital stay, than open approach.

\section{Robotic vs. conventional laparoscopic partial hepatectomy}

Traditionally, conventional laparoscopic partial hepatectomy can either be pure laparoscopic or handassisted laparoscopic approach. Techniques of handassisted laparoscopic approach has been attempted to bridge the gap between open and pure laparoscopic approach. The benefits of hand-assisted laparoscopic approach in hepatectomy are: (1) facilitation in manual retraction, which may be the best atraumatic tool; (2) feasibility in assessing margins of resection with the use of tactile sensation; (3) safety in parenchymal dissection laparoscopically; and (4) possibility of immediate hemostasis and prevents air embolism in case the hepatic vein is severed. Obviously, pure laparoscopic procedure is superior to hand-assisted approach in terms of wound pain, and cosmetic outcome as hand-assisted laparoscopic hepatectomy usually required a $6-8 \mathrm{~cm}$ incision for the placement of the hand-port. Another possible disadvantage of hand-assisted laparoscopic approach includes possible obstruction of the visual field by the surgeon's hand during the operation. Based on the platform of the development and experiences of conventional laparoscopic hepatectomy, robotic surgical system was developed to overcome the disadvantages of conventional laparoscopic approach and handassisted laparoscopic approach. When robotic system compared to conventional laparoscopic approach, the pros and cons of each approach were shown in Table 2. Robot-assisted laparoscopic partial hepatectomy was increasingly studied in recent years. Up till now, no randomized trials are available for robotic hepatectomy. All data have been reported as case series or nonrandomized comparative studies. Most data were obtained from prospectively maintained databases. Tables 3 and 4 showed the results of nonrandomized comparative studies comparing robotic and laparoscopic partial hepatectomy in patients with minor hepatectomies ${ }^{[18-25]}$ and in patients with minor and major hepatectomies ${ }^{[26-29]}$. Although the perioperative outcomes seemed to be similar in both groups, the benefit of robotic approach has been shown in several studies. The potential benefits included less open conversion rate, higher proportion of major hepatectomies and easier for resection of those tumours located over superior and posterior segments ${ }^{[22,26,28,30-33]}$.

Based on current nonrandomized comparative studies, robot-assisted laparoscopic partial hepatectomy appears to be similar to conventional laparoscopic approach in terms of blood loss, morbidity, mortality rate and hospital stay. Robot-assisted laparoscopic hepatectomy may have longer operation time. However, the definition of operation time was variable. Some authors refer to a "total operation time" and specify an included "robot set-up and docking time", whereas others refer to a "procedure time" with a separate "system time" (from positioning the robot over the patient to disconnection of the robot) and "dissection time" (surgeon's active time at the console); others calculate the time from "induction of anesthesia to incision" or from "incision to extubation". However, robotic approach is more expensive than laparoscopic approach. 
Table 3: Nonrandomized comparative studies comparing robotic and laparoscopic minor hepatectomy

\begin{tabular}{|c|c|c|c|c|c|c|c|c|c|}
\hline Studies & $n$ & $\begin{array}{l}\text { Operating } \\
\text { time (min) }\end{array}$ & $\begin{array}{l}\text { Blood loss } \\
\quad(\mathrm{mL})\end{array}$ & $\begin{array}{c}\text { Conversion } \\
(\%)\end{array}$ & $\begin{array}{c}\text { Complication } \\
(\%)\end{array}$ & $\begin{array}{c}\text { Mortality } \\
(\%)\end{array}$ & $\begin{array}{l}\text { Hospital } \\
\text { stay } \\
\text { (days) }\end{array}$ & $\begin{array}{c}\text { R0 } \\
\text { resection } \\
(\%)\end{array}$ & Cost \\
\hline Berber et al. ${ }^{[18]}(2010)$ & 9 vs. 23 & $\begin{array}{c}258.5 \text { vs. } \\
233.6\end{array}$ & 136 vs. 155 & 11.1 vs. 0 & 11 vs. 17 & 1 & 1 & 1 & 1 \\
\hline Packiam et al. ${ }^{[19]}$ (2012) & 11 vs. 18 & 175 vs. 188 & 0 & 0 & 27 vs. $0^{*}$ & 0 & $4 \mathrm{vs}$ & 1 & $\begin{array}{c}\$ 6,553 \text { vs. } \\
\$ 4,408^{*}\end{array}$ \\
\hline Lai et al. ${ }^{[20]}(2013)$ & 33 vs. 33 & $\begin{array}{c}202.7 \text { vs. } \\
133.4^{*}\end{array}$ & $\begin{array}{c}373.4 \text { vs. } \\
347.7\end{array}$ & 1 & 3 vs. 9 & 0 & 1 & $\begin{array}{c}90.9 \text { vs. } \\
90.9\end{array}$ & 1 \\
\hline Tranchart et al. ${ }^{[21]}(2014)$ & 28 vs. 28 & $\begin{array}{c}210 \text { vs. } 176 \\
\text { (median) }\end{array}$ & 200 vs. 150 & 14.3 vs. 7.1 & 17.9 vs. 17.9 & 0 vs. 0 & 4.5 vs. 3 & 1 & 1 \\
\hline Yu et al. ${ }^{[2]}(2014)$ & 13 vs. 17 & $\begin{array}{c}291.5 \text { vs. } \\
240.9^{*}\end{array}$ & $\begin{array}{c}388.5 \text { vs. } \\
342.6\end{array}$ & 0 vs. 0 & 0 vs. 11.8 & 0 vs. 0 & $\begin{array}{c}7.8 \text { vs. } \\
9.5\end{array}$ & 1 & $\begin{array}{c}\$ 11,475 \text { vs. } \\
\$ 6,762^{*}\end{array}$ \\
\hline Kim et al. ${ }^{[23]}(2016)$ & 12 vs. 31 & $\begin{array}{c}337.4 \text { vs. } \\
216.4^{*}\end{array}$ & $\begin{array}{l}225 \text { vs. } 150 \\
\text { (median) }\end{array}$ & 0 vs. 3.2 & 25 vs. 22.6 & 0 vs. 0 & 7 vs. 7 & 1 & $\begin{array}{c}\$ 8,183 \text { vs. } \\
\$ 5,190^{*}\end{array}$ \\
\hline Montalti et al. ${ }^{[2]}(2016)$ & 36 vs. 72 & 306 vs. 295 & 415 vs. 437 & 13.9 vs. 9.7 & 19.4 vs. 19.4 & 2.8 vs. 0 & 6 vs. 4.9 & $\begin{array}{c}88.9 \text { vs. } \\
87.5\end{array}$ & 1 \\
\hline Salloum et al. ${ }^{[25]}(2017)$ & 16 vs. 80 & 190 vs. 162 & 247 vs. 206 & 13 vs. 3 & 13 vs. 11 & 0 vs. 1 & 6 vs. 7 & 100 vs. 98 & $\begin{array}{c}€ 5,522 \text { vs. } \\
€ 6,035\end{array}$ \\
\hline
\end{tabular}

${ }^{*} P<0.05$

Table 4: Nonrandomized comparative studies comparing robotic and laparoscopic minor and major hepatectomy

\begin{tabular}{|c|c|c|c|c|c|c|c|c|c|}
\hline Studies & $n$ & $\begin{array}{l}\text { Operating } \\
\text { time (min) }\end{array}$ & $\begin{array}{l}\text { Blood loss } \\
\text { (mL) }\end{array}$ & $\begin{array}{c}\text { Conversion } \\
(\%)\end{array}$ & $\begin{array}{c}\text { Complication } \\
(\%)\end{array}$ & $\begin{array}{c}\text { Mortality } \\
(\%)\end{array}$ & $\begin{array}{l}\text { Hospital } \\
\text { stay } \\
\text { (days) }\end{array}$ & $\begin{array}{c}\mathbf{R 0} \\
\text { resection } \\
(\%)\end{array}$ & Cost \\
\hline Tsung et al. ${ }^{[26]}(2014)$ & 57 vs. 114 & $\begin{array}{l}253 \text { vs. } \\
198.5^{\star}\end{array}$ & 200 vs. 100 & 7 vs. 8.8 & 19.3 vs. 26 & 0 vs. 1.8 & $\begin{array}{c}4 \text { vs. } 4 \\
\text { (median) }\end{array}$ & 95 vs. 92 & 1 \\
\hline Spampinato et al. ${ }^{[27]}(2014)$ & 25 vs. 25 & 430 vs. 360 & 250 vs. 400 & 4 vs. 4 & 16 vs. 36 & 0 vs. 4 & 8 vs. 7 & 100 vs. 91 & 1 \\
\hline Wu et al. ${ }^{[28]}(2014)$ & 38 vs. 41 & 380 vs. $227^{*}$ & 325 vs. $173^{*}$ & 5 vs. 12.2 & 8 vs. 10 & 0 vs. 0 & 7.9 vs. 7.2 & 1 & 1 \\
\hline Lee et al. ${ }^{[29]}(2016)$ & 70 vs. 66 & $\begin{array}{c}251.5 \text { vs. } \\
215^{\star}\end{array}$ & $\begin{array}{c}100 \text { vs. } 100 \\
\text { (median) }\end{array}$ & 5.7 vs. 12.1 & 11.4 vs. 4.5 & 0 vs. 0 & 5 vs. 5 & 1 & 1 \\
\hline
\end{tabular}

${ }^{*} P<0.05$

\section{ONCOLOGICAL OUTCOMES}

At present, available survival data about robotic partial hepatectomy for HCC in the literature are limited still. Difficult learning curves, adequate resection margins, tumor seeding, metastases of the wounds, and the long-term outcome are the major concerns. No portsite recurrence was reported. However, specific survival data in homogenous group of pathology was very limited. The majority of the papers included deals with patients undergoing robotic partial hepatectomy for different diseases, whereas HCC represent a variable (often small) proportion of the total. Therefore, a meaningful analysis of survival data for HCC after robotic surgery was difficult still.

\section{Robotic vs. open approach for HCC}

In Chen et al. ${ }^{[33]}$, a total of 183 patients underwent robotic partial hepatectomy and 275 patients underwent open partial hepatectomy by the same surgical team between January 2012 and October 2015. Eightyone newly diagnosed HCC cases in each group were compared under propensity score matching in a 1:1 ratio. With robotic partial hepatectomy, the conversion rate was $1.6 \%$ and the complication rate was $4.4 \%$. The two groups had a comparable percentage of major partial hepatectomy (41.9\% vs. $39.5 \%)$ and liver cirrhosis (45.7\% vs. $46.9 \%)$. Compared with the open group, the robotic group required longer operating times (343 vs. $220 \mathrm{~min}$ ), shorter hospital stay (7.5 vs. 10.1 days), and lower dosages of postoperative patient-controlled analgesia (350 vs. $554 \mathrm{ng} / \mathrm{kg}$ ). The 3 -year disease-free survival of the robotic group was comparable with that of the open group $(72.2 \% \mathrm{vs}$. $58.0 \%$ ), and also similar in the 3-year overall survival (92.6\% vs. 93.7\%).

\section{Robotic vs. conventional laparoscopic} approach for HCC

In 2013, the short-term survival outcome after robotic partial hepatectomies for 41 consecutive patients with HCC was reported by Lai et al. ${ }^{[20]}$. The mean operation time and blood loss was $229.4 \mathrm{~min}$ and $412.6 \mathrm{~mL}$, respectively. The $\mathrm{R} 0$ resection rate was $93 \%$. The hospital mortality and morbidity rates were $0 \%$ and $7.1 \%$, respectively. The mean hospital stay was 6.2 days. The 2-year overall and disease-free survival rates were $94 \%$ and $74 \%$, respectively. In the subgroup 
analysis of minor hepatectomies, when compared with the conventional laparoscopic approach, the robotic group had similar blood loss (mean, 373.4 vs. 347.7 $\mathrm{mL})$, morbidity rate $(3 \%$ vs. $9 \%)$, mortality rate $(0 \%$ vs. $0 \%)$, and R0 resection rate $(90.9 \%$ vs. $90.9 \%)$. However, the robotic group had a significantly longer operative time (202.7 vs. 133.4 min). Recently, Lai and Tang $^{[34]}$ also compared the long-term oncological outcomes of robotic $(n=100)$ and conventional laparoscopic partial hepatectomy $(n=35)$ for HCC. Robotic group had a significant higher proportion of major hepatectomies ( $27 \%$ vs. $2.9 \%$ ) and tumors located at or across posterosuperior segments $(29 \%$ vs. 0\%) than conventional laparoscopic group. For the perioperative outcomes, robotic group had a significant longer mean operating time (207.4 vs. $134.2 \mathrm{~min}$ ). Both groups had similar blood loss (334.6 vs. $336 \mathrm{~mL}$ ). There was no difference in morbidity (14\% vs. $20 \%)$ and mortality rate $(0 \%$ vs. $0 \%)$. Concerning oncological outcomes, there was no difference between 2 groups in $\mathrm{R0}$ resection rate (96\% vs. $91.4 \%)$, 5-year overall survival ( $65 \%$ vs. $48 \%)$, and disease-free survival $(42 \%$ vs. $38 \%$ ). Recently, Magistri et al. ${ }^{[35]}$ also reported the short-term outcomes of patients who had underwent robotic resections $(n=22)$ and laparoscopic $(n=24)$ resections for HCC. In the robotic group, there were 6 left lateral sectionectomies, 2 right hepatectomies, and 14 minor resections, including 9 segmentectomies and 5 wedge resections. In the laparoscopic group, there were 14 segmentectomies and 10 wedge resections, but no major hepatectomies. Operating time was significantly longer in the robotic group (318 vs. $211 \mathrm{~min}$ ), whereas estimated blood loss was comparable between the two groups (400 vs. $320 \mathrm{~mL}$ ), with one case needed blood transfusion in each group. In the robotic group, Clavien-Dindo classes I and II complication was significantly less frequent than in the laparoscopic group ( $n=13$ vs. $n=22$ ). During analyzing specific complications, pleural effusion was significantly less frequent in the robotic group $(n=2$ vs. $n=10$ ). Regarding major complications, there were no differences of incidence among the two cohorts ( $n=2$ vs. $n=3$ ). In both the groups, one case of R1 resection was observed. They also found that robotic surgery allowed the surgeon to safely deal with liver segments that are difficult to resect in laparoscopic approach, such as segments I-VII-VIII.

\section{CONCLUSION}

Although little data regarding robotic liver surgery have been reported, it appears to be superior to open approach, particularly blood loss and hospital stay, and similar to conventional laparoscopic approach in terms of operative time, blood loss, morbidity rate, mortality rate and hospital stay. However, robotic surgery is more expensive than conventional laparoscopic approach. It should be emphasized that considering robot-assisted laparoscopic partial hepatectomy requires 4 conditions: (1) appropriate selection of patients; (2) follow the principle of open liver surgery; (3) specific expertise and training, in both liver and laparoscopic surgery; and (4) familiarization with the robotic machine and pay precaution of its potential dangers, such as visceral injury by robotic arm, total loss of tactile feedback. For the oncological outcome for robotic resection of HCC, the data are very limited. Oncological data from homogenous series of HCC after robotic partial hepatectomy was needed. Its future implementation and clinical value will depend on the advantages that it can provide over conventional laparoscopy or open surgery.

\section{DECLARATIONS}

\section{Authors' contributions}

Proposed the idea, structure, and content: E.C.H. Lai Literature search: E.C.H. Lai, D.T.M. Chung, O.C.Y. Chan

First draft: E.C.H. Lai

Revision and final proof read: D.T.M. Chung, O.C.Y. Chan, C.N. Tang

\section{Financial support and sponsorship \\ None.}

\section{Conflicts of interest}

There are no conflicts of interest.

\section{Patient consent}

Not applicable.

\section{Ethics approval \\ Not applicable.}

\section{REFERENCES}

1. Lai EC, Tang CN, Yang GP, Li MK. Multimodality laparoscopic liver resection for hepatic malignancy--from conventional total laparoscopic approach to robot-assisted laparoscopic approach. Int $J$ Surg 2011;9:324-8.

2. Lai EC, Tang CN, Li MK. Conventional laparoscopic and robotassisted laparoscopic liver resection for benign and malignant pathologies: a cohort study. $J$ Robot Surg 2012;6:295-300.

3. Buell JF, Cherqui D, Geller DA, O'Rourke N, Iannitti D, Dagher I, Koffron AJ, Thomas M, Gayet B, Han HS, Wakabayashi G, Belli G, Kaneko H, Ker CG,Scatton O, Laurent A, Abdalla EK, Chaudhury P, Dutson E, Gamblin C, D’Angelica M, Nagorney D, Testa G, Labow D, Manas D, Poon RT, Nelson H, Martin R, Clary B, Pinson WC, Martinie J, Vauthey JN, Goldstein R, Roayaie S, Barlet D, Espat J, Abecassis M, Rees M, Fong Y, McMasters KM, Broelsch C, Busuttil R, Belghiti J, Strasberg S, Chari RS; World Consensus Conference on 
Laparoscopic Surgery. The international position on laparoscopic liver surgery: The Louisville Statement, 2008. Ann Surg 2009;250:825-30.

4. Wakabayashi G, Cherqui D, Geller DA, Buell JF, Kaneko H, Han HS, Asbun H, O’Rourke N, Tanabe M, Koffron AJ, Tsung A, Soubrane O, Machado MA, Gayet B, Troisi RI, Pessaux P, Van Dam RM, Scatton O, Abu Hilal M, Belli G, Kwon CH, Edwin B, Choi GH, Aldrighetti LA, Cai X, Cleary S, Chen KH, Schön MR, Sugioka A, Tang CN, Herman P, Pekolj J, Chen XP, Dagher I, Jarnagin W, Yamamoto M, Strong R, Jagannath P, Lo CM, Clavien PA, Kokudo N, Barkun J, Strasberg SM. Recommendations for laparoscopic liver resection: a report from the second international consensus conference held in Morioka. Ann Surg 2015;261:619-29.

5. Ciria R, Cherqui D, Geller DA, Briceno J, Wakabayashi G. comparative short-term benefits of laparoscopic liver resection: 9000 cases and climbing. Ann Surg 2016;263:761-77.

6. Lai EC, Lau WY. The continuing challenge of hepatic cancer in Asia. Surgeon 2005;3:210-5

7. Lau WY, Lai EC. Hepatocellular carcinoma: current management and recent advances. Hepatobiliary Pancreat Dis Int 2008;7:237-57.

8. Lau WY, Lai EC. The current role of radiofrequency ablation in the management of hepatocellular carcinoma: a systematic review. Ann Surg 2009;249:20-5

9. Lai EC, Tang CN, Yang GP, Li MK. Minimally invasive surgical treatment of hepatocellular carcinoma: long-term outcome. World $J$ Surg 2009;33:2150-4

10. Lai EC, Tang CN, Ha JP, Li MK. Laparoscopic liver resection for hepatocellular carcinoma: ten-year experience in a single center. Arch Surg 2009;144:143-7.

11. Lai EC, Tang CN. Radiofrequency ablation versus hepatic resection for hepatocellular carcinoma within the Milan criteria--a comparative study. Int J Surg 2013;11:77-80.

12. Zhou YM, Shao WY, Zhao YF, Xu DH, Li B. Meta-analysis of laparoscopic versus open resection for hepatocellular carcinoma. Dig Dis Sci 2011;56:1937-43.

13. Yin Z, Fan X, Ye H, Yin D, Wang J. Short- and long-term outcomes after laparoscopic and open hepatectomy for hepatocellular carcinoma: a global systematic review and meta-analysis. Ann Surg Oncol 2013;20:1203-15.

14. Twaij A, Pucher PH, Sodergren MH, Gall T, Darzi A, Jiao LR. Laparoscopic vs open approach to resection of hepatocellular carcinoma in patients with known cirrhosis: systematic review and meta-analysis. World J Gastroenterol 2014;20:8274-81

15. Patriti A, Cipriani F, Ratti F, Bartoli A, Ceccarelli G, Casciola L, Aldrighetti L. Robot-assisted versus open liver resection in the right posterior section. JSLS 2014;18:e2014.00040.

16. Kingham TP, Leung U, Kuk D, Gönen M, D'Angelica MI, Allen PJ, DeMatteo RP, Laudone VP, Jarnagin WR, Fong Y. Robotic liver resection: a case-matched comparison. World J Surg 2016;40:1422-8.

17. Daskalaki D, Gonzalez-Heredia R, Brown M, Bianco FM, Tzvetanov I, Davis M, Kim J, Benedetti E, Giulianotti PC. Financial impact of the robotic approach in liver surgery: a comparative study of clinical outcomes and costs between the robotic and open technique in a single institution. J Laparoendosc Adv Surg Tech A 2017;27:375-82.

18. Berber E, Akyildiz HY, Aucejo F, Gunasekaran G, Chalikonda S, Fung J. Robotic versus laparoscopic resection of liver tumours. HPB (Oxford) 2010;12:583-6.

19. Packiam V, Bartlett DL, Tohme S, Reddy S, Marsh JW, Geller
DA, Tsung A. Minimally invasive liver resection: robotic versus laparoscopic left lateral sectionectomy. $J$ Gastrointest Surg 2012;16:2233-8

20. Lai EC, Yang GP, Tang CN. Robot-assisted laparoscopic liver resection for hepatocellular carcinoma: short-term outcome. Am J Surg 2013;205:697-702.

21. Tranchart H, Ceribelli C, Ferretti S, Dagher I, Patriti A. Traditional versus robot-assisted full laparoscopic liver resection: a matched-pair comparative study. World J Surg 2014;38:2904-9.

22. Yu YD, Kim KH, Jung DH, Namkoong JM, Yoon SY, Jung SW Lee SK, Lee SG. Robotic versus laparoscopic liver resection: a comparative study from a single center. Langenbecks Arch Surg 2014;399:1039-45.

23. Kim JK, Park JS, Han DH, Choi GH, Kim KS, Choi JS, Yoon DS Robotic versus laparoscopic left lateral sectionectomy of liver. Surg Endosc 2016;30:4756-64

24. Montalti R, Scuderi V, Patriti A, Vivarelli M, Troisi RI. Robotic versus laparoscopic resections of posterosuperior segments of the liver: a propensity score-matched comparison. Surg Endosc 2016;30:100413.

25. Salloum C, Lim C, Lahat E, Gavara CG, Levesque E, Compagnon P, Azoulay D. Robotic-assisted versus laparoscopic left lateral sectionectomy: analysis of surgical outcomes and costs by a propensity score matched cohort study. World J Surg 2017;41:516-24.

26. Tsung A, Geller DA, Sukato DC, Sabbaghian S, Tohme S, Stee J, Marsh W, Reddy SK, Bartlett DL. Robotic versus laparoscopic hepatectomy: a matched comparison. Ann Surg 2014;259:549-55

27. Spampinato MG, Coratti A, Bianco L, Caniglia F, Laurenzi A, Puleo F, Ettorre GM, Boggi U. Perioperative outcomes of laparoscopic and robot-assisted major hepatectomies: an Italian multi-institutional comparative study. Surg Endosc 2014;28:2973-9.

28. Wu YM, Hu RH, Lai HS, Lee PH. Robotic-assisted minimally invasive liver resection. Asian J Surg 2014;37:53-7.

29. Lee KF, Cheung YS, Chong CC, Wong J, Fong AK, Lai PB Laparoscopic and robotic hepatectomy: experience from a single centre. ANZ J Surg 2016;86:122-6.

30. Lai EC, Tang CN. Robot-assisted laparoscopic partial caudate lobe resection for hepatocellular carcinoma in cirrhotic liver. Surg Laparosc Endosc Percutan Tech 2014;24:e88-91.

31. Lai EC, Tang CN, Li MK. Robot-assisted laparoscopic hemihepatectomy: technique and surgical outcomes. Int J Surg 2012;10:115

32. Casciola L, Patriti A, Ceccarelli G, Bartoli A, Ceribelli C, Spaziani A Robot-assisted parenchymal-sparing liver surgery including lesions located in the posterosuperior segments. Surg Endosc 2011;25:381524.

33. Chen PD, Wu CY, Hu RH, Chou WH, Lai HS, Liang JT, Lee PH, Wu YM. robotic versus open hepatectomy for hepatocellular carcinoma: a matched comparison. Ann Surg Oncol 2017;24:1021-8

34. Lai EC, Tang CN. Long-term survival analysis of robotic versus conventional laparoscopic hepatectomy for hepatocellular carcinoma: a comparative study. Surg Laparosc Endosc Percutan Tech 2016;26:162-6.

35. Magistri P, Tarantino G, Guidetti C, Assirati G, Olivieri T, Ballarin $\mathrm{R}$, Coratti A, Di Benedetto F. Laparoscopic versus robotic surgery for hepatocellular carcinoma: the first 46 consecutive cases. J Surg Res 2017;217:92-9. 